\title{
Faults diagnosis in stator windings of high speed solid rotor induction motors using fuzzy neural network
}

\author{
Ahmed Thamer Radhi, Wael Hussein Zayer \\ Department of Electromechanical Engineering, Engineering Technical College of Misan, Southern Technical University, \\ Basrah, Iraq
}

\begin{tabular}{l} 
Article Info \\
\hline Article history: \\
Received Oct 20, 2020 \\
Revised Jan 26, 2021 \\
Accepted Feb 6, 2021 \\
\hline
\end{tabular}

Keywords:

Equivalent circuit

Fault diagnosis

Fuzzy neural network

Solid rotor

Stator winding turn fault

\begin{abstract}
The paper deals with faults diagnosis method proposed to detect the interturn and turn to earth short circuit in stator winding of three-phase highspeed solid rotor induction motors. This method based on negative sequence current of motor and fuzzy neural network algorithm. On the basis of analysis of 2-D electromagnet field in the solid rotor the rotor impedance has been derived to develop the solid rotor induction motor equivalent circuit. The motor equivalent circuit is simulated by MATLAB software to study and record the data for training and testing the proposed diagnosis method. The numerical results of proposed approach are evaluated using simulation of a three-phase high-speed solid-rotor induction motor of two-pole, $140 \mathrm{~Hz}$. The results of simulation shows that the proposed diagnosis method is fast and efficient for detecting inter-turn and turn to earth faults in stator winding of high-speed solid-rotor induction motors with different faults conditions.
\end{abstract}

This is an open access article under the CC BY-SA license.

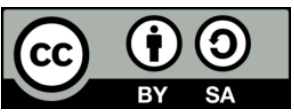

\section{Corresponding Author:}

Ahmed Thamer Radhi

Department of Electromechanical Engineering

Engineering Technical College of Misan

Southern Technical University, Basrah, Iraq

Email: ahmed.radhi@stu.edu.iq

\section{INTRODUCTION}

A high-speed motor applications in the medium and large power range has been increasingly commonly within the latest decade. The development in the power level into modern electronics convertors has been given the possibility for replacing conventional gas turbines with high power and high speed electric motors used for example in large gas compression system. The demand of high-speed direct drive systems has been increasing the effort of research in the field of high-speed electrical motors. The induction motors are very competitive with high-speed applications. The simple structure of rotating part of solid rotor induction motors is push to achieve the speed limit. A mild steel solid rotor can be used instead of a cage rotor to achieve the high-speed induction motors. The applications of solid rotor induction motors in turbocharger, compressors, pumping system, and drilling system which are applied due to easy to manufacture, suitable of operation in severe environment and highly reliable. More particularly, seem to be the most important area in which high speed motors are used in the applications which involved with gas movement and compression.

In manufacturing the design of rotor core from one piece of steel it is possible to achieve the highspeed motor with an extremely rigid rotor construction. The solid rotor has electromagnetic properties are poorer than an induction motor with laminated rotor. The effect study of slitted solid rotor axial length on the performance of induction motor has been introduced by [1], it found that the efficiency of the motor is increased with shorten length of solid rotor end. The two-dimension finite element method is used for 
frequency dependent end factor correction is presented in [2] for accurately calculation of electromagnetic torque and power factor for modern design of high speed solid rotor induction motors. In [3] has been proposed the design analytical method and prediction of characteristics of induction motors of solid steel rotor. The 2-D electromagnetic field distribution is used to drive the rotor equivalent impedance, also edge effect and solid steel nonlinear magnetic permeability have been included. In [4] has been proposed a multiphysics approach for analysing and testing the performance of a high speed induction motors with a solid rotor, the theoretical background and aspects of solid rotor design were presented considering electromagnetic field into solid rotor, mechanical aspects of the rotor and concentrating on the effects of endregion. In [5] fuzzy logic and neural network method were applied for fault detection into stator winding in permanent magnet synchronous motors PMSM in which negative sequence current and its impedance are used to generate detection decision by fuzzy logic. Application of high frequency voltage based stator winding diagnosis method for induction machines operating by inverters has been presents in [6] depending on negative sequence current which contain information on fault level in the machine. Bare-Bones Particle Swarm Optimization BBPSO and cross-validation method were proposed by [7], to reach the optimal Support Vector Machine SVM parameters, the SVM is optimized with BBPSO were applied to diagnosis inter-turn fault in winding of induction motors.

A finite element method was presents in [8] to assessment the broken rotor bars effect on stator currents in induction motors by current harmonics calculation due to rotor fault. In [9] method of monitoring and detection of fault in single phase induction motor has been proposed for stator inter-turn faults diagnosis by artificial neural network. Overview of fault diagnosis in permanent magnet induction machines was giving in [10] in which different methods of fault diagnosis are introduced, analyzed and compared. Automatic approach of inter-turn fault detection and severity classification in stator winding of PMSM using an artificial neural network ANN for pattern recognition system were presented by [11]. In [12] has been used selforganizing feature map neural network to detect the faults in stator winding of PMSM based on wavelet transform for current feature extraction. A survey of different diagnosis methods for various faults type in induction motors was introduced by [13]. In [14] ANN is used to diagnosis and segregate faults in induction motors for improving the traditional methods since it is better solution to statistical analyzing. In [15] was proposed a new method of asymmetry detection in stator winding and localization of faults in PMSM controlled via Field-Oriented control. The proposed method based on a negative-sequence current polar coordinate and the optimizing process of fault localization is adopted by Neuro-fuzzy system. In [16] presents a stator winding short circuit fault diagnosis in PMSM using neural network by taken motor currents as input to the proposed method. In [17] a review of faults detection methods in PMSM are introduced also fault performance summarization of recently proposed algorithms are recorded. A stator winding inters turn fault detection method using current sequence component value to classify the fault with ANN has been presents in [18]. Stator winding fault detection method in PMSM based on empirical mode decomposition analysis of transient motor current was presents in [19] with finite elements method is used for model's simulation. In [20] a nonlinear observer technique based on neural network and Cuckoo search algorithm is presented for fault diagnosis in induction motors which is mixes ANN with analytical model. A study for faults monitoring in stator and rotor of induction motors with voltage source inverters is proposed in [21] based on analysis of torque spectrum using full-order flux observer. A novel fault diagnosis and localization approach is used to detect and localize asymmetry in stator winding of induction motor is introduced by [22]. The proposed method based on Fast Fourier Transform FFT analysis of motor three-phase currents as feature extraction to feed the algorithm of Fuzzy Neural Petri Net FNPN which is used to detect and localize the fault.

Stator winding faults such as inter-turn and turn to earth short circuits are almost more than $70 \%$ of induction motor faults. Stator winding faults lead to winding resistance variation and produce phase unbalance due to the phase impedances of three phases are not equal. In these conditions the balance of stator winding of the motor is lost and a rotating magnetic field in a reverse direction i.e. negative sequence field is produced leading to additional stress of electromagnetic field. The unbalance of the phase impedances which affect the motor efficiency and causing unbalanced motor currents and voltages. Also, fault has been affect on different motor variables such as air-gap flux and electromagnetic torque. In recent applications a solid rotor induction motors topologies operating with high-speed drive it's gained a lot of interest as direct drive compressors, superconducting machines and high-speed generators, therefore, a fast diagnosis of small initial faults in stator winding is important to prevent a consequence large damage in motor winding. For these reasons, this research is interested to proposed stator winding fault diagnosis method for high-speed solid rotor induction motors have been developed to detect inter-turn and turn to earth short circuits with winding percent of $3 \%, 5 \%, 7 \%, 10 \%, 13 \%, 15 \%, 17 \%$, and $20 \%$, the phase to phase faults are not considered in this research. The proposed method is depending on amplitude and phase angle of negative sequence current for motor currents which are recorded from simulated equivalent circuit model of motor by MATLAB/simulink. 
A fuzzy neural network FNN algorithm is used to diagnosis the faults in stator winding at different conditions depends on amplitude and phase angle of negative sequence current which are used as an input to the FNN diagnosis network. This paper is organized as follows, solid rotor electromagnetic analysis and equivalent circuit model are presents in section 2. Section 3 introduces the Fuzzy Neural network FNN architecture and training algorithm. The proposed faults diagnosis approach is giving in section 5. Section 6 explains the simulated model of solid rotor induction motor using MATLAB/simulink. In section 7 the training of proposed FNN algorithm has been executed. Tests results are evaluated and discussed in section 8 . Finally, the conclusions are drawn in section 9.

\section{SOLID ROTOR INDUCTION MOTOR}

A Solid rotor induction motors are reliable and cheap alternative to induction motors with cage rotor due to their simple structure of solid rotor and extremely rigid. Despite of the principle of solid rotor induction motor operation is the same to other induction motors, magnetic field, temperature, mechanical stresses and current density are peculiar in the structure of rotor and have to be verificated carefully to achieve good motor performance [4]. The electromagnetic characteristic of the rotor material is important which it affect the distribution of field in the solid rotor structure and have to withstand maximum stresses which is featured in the rotor. Electromagnetic modeling of solid rotor induction machine is one of the analysis methods has been used to calculate the rotor impedance of the motor is described in the next sections.

\subsection{Electromagnetic model}

The performance investigation of solid rotor induction motor has been adopted with many approaches. An analytical method [3] is quick but due to many assumptions is considered its involving lose in accuracy, the analytically calculated field distribution may be used for estimating the motor equivalent circuit parameters. Time-harmonic Finite Element Method FEM simulations are requiring an accurate materials modeling and sometimes the solutions are difficult because the non-linearity characteristics of the problem [1]. Finite Difference Method [23] is reasonably fast technique and an accurate for determining the distribution of field in the structure of rotor but when the high space harmonics numbers are considered the accuracy is decreases. A full 3-D time-stepping analysis of solid rotor structures would still be very demanding problem to solve in reasonable time. For this reason, the electromagnetic analysis of field in solid rotor is calculated with 2-D representation. Equivalent circuit method can be used to calculate the solid rotor induction motor performance based on 2-D electromagnetic field analysis of rotor. It is possible to model solid rotor induction motor using an equivalent circuit to investigate its performances.

\subsection{Equivalent circuit}

The operation principle of high speed solid-rotor induction motors is like to other induction motors, but, problems arise with the analysis of solid rotor due to both nonlinearity of ferromagnetic material of solid rotor and complexity of structure for certain types of these motors. The rotor electromagnetic field is strongly $3-\mathrm{D}$, although the stator rotating magnetic field can be assumed to be 2-D. Based on the analysis of distribution 2-D electromagnetic field in the machine, the rotor impedance has been derived for fundamental field and balanced three-phase system, for ferromagnetic rotor material the complex propagation constant is given as [3]:

$$
\alpha_{\mathrm{Fe}}=\sqrt{j w \mu_{0} \mu_{\mathrm{rs}} \sigma_{\mathrm{Fe}}}=\left(\mathrm{a}_{\mathrm{R}}+\mathrm{ja} \mathrm{a}_{\mathrm{x}}\right) \mathrm{k}_{\mathrm{Fe}}
$$

Where $\mathrm{w}$ is the angular frequency $(\mathrm{rad} / \mathrm{s}), \mu_{0}$ is the free space magnetic permeability $(\mathrm{H} / \mathrm{m}), \mu_{\mathrm{rs}}$ is the relative magnetic permeability of surface $(\mathrm{H} / \mathrm{m}), \sigma_{\mathrm{Fe}}$ is the conductivity of rotor $(\mathrm{S} / \mathrm{m}), \mathrm{a}_{\mathrm{R}}$ is the resistance coefficient for including hysteresis losses and nonlinear magnetic permeability, $a_{\mathrm{x}}$ is the reactance coefficient for including hysteresis losses and nonlinear magnetic permeability and $\mathrm{k}_{\mathrm{Fe}}$ is the electromagnetic field attenuation coefficient $(1 / \mathrm{m})$.

The conductive medium attenuation coefficient with its conductivity and magnetic permeability is given by:

$$
\mathrm{k}_{\mathrm{Fe}}=\sqrt{\frac{\mathrm{w} \mu_{0} \mu_{\mathrm{rs}} \sigma_{\mathrm{Fe}}}{2}}
$$

The rotor impedance has been derived for fundamental field and balanced three-phase system is given by [3]:

Faults diagnosis in stator windings of high speed solid rotor induction motors ... (Ahmed Thamer Radhi) 
$\mathrm{Z}_{\mathrm{r}}=\frac{j w \mu_{\mathrm{Fe}}}{\mathrm{k}_{\mathrm{Fe}}} \frac{\mathrm{L}}{\tau}=\frac{j w \mu_{\mathrm{Fe}} \sigma_{\mathrm{Fe}}}{\mathrm{k}_{\mathrm{Fe}} \sigma_{\mathrm{Fe}}} \frac{\mathrm{L}}{\tau} \approx \frac{\alpha_{\mathrm{Fe}}}{\sigma_{\mathrm{Fe}}} \frac{\mathrm{L}}{\tau}$

Where $\mathrm{L}$ is the rotor length $(\mathrm{m})$ and $\tau$ is the pole pitch $(\mathrm{m})$.

Substituting (1) and (2) into (3), respectively, the new expression of $\mathrm{Zr}$ is equal to:

$\mathrm{Z}_{\mathrm{r}}=\left(\mathrm{a}_{\mathrm{R}}+\mathrm{ja} \mathrm{a}_{\mathrm{x}}\right) \frac{\mathrm{L}}{\tau} \sqrt{\frac{\mathrm{w} \mu_{0} \mu_{\mathrm{rs}}}{2 \sigma_{\mathrm{Fe}}}}$

The angular frequency of rotor $\mathrm{w}=2 \pi \mathrm{f}_{\mathrm{r}}$, where $\mathrm{f}_{r}$ is the rotor frequency $(\mathrm{Hz})$, for rotating field of positive sequence $f_{r}^{+}=s f$ and for rotating field of negative sequence $f_{r}^{-}=(2-s) f$, substituting into (4), yields:

$$
\mathrm{Z}_{\mathrm{r}}=\left(\mathrm{a}_{\mathrm{R}}+\mathrm{ja} \mathrm{a}_{\mathrm{x}}\right) \frac{\mathrm{L}}{\tau} \sqrt{\frac{\pi \mathrm{f}_{\mathrm{r}} \mu_{0} \mu_{\mathrm{rs}}}{\sigma_{\mathrm{Fe}}}}
$$

To include the edge effect, solid steel conductivity $\sigma_{\mathrm{Fe}}$ in $\mathrm{k}_{\mathrm{Fe}}$ parameter must be multiplied with the square of edge factor reciprocal $\mathrm{k}_{\mathrm{z}}$ :

$$
\sigma_{\mathrm{Fe}}=\frac{\sigma_{\mathrm{Fe}}}{\mathrm{k}_{\mathrm{z}}{ }^{2}}
$$

where $\mathrm{k}_{\mathrm{z}}=1+\frac{2}{\pi} \frac{\tau}{\mathrm{L}}$

substituting (6) into (5), yields:

$$
\mathrm{Z}_{\mathrm{r}}=\left(\mathrm{a}_{\mathrm{R}}+\mathrm{ja} \mathrm{a}_{\mathrm{x}}\right) \mathrm{k}_{\mathrm{z}} \frac{\mathrm{L}}{\tau} \sqrt{\frac{\pi \mathrm{f}_{\mathrm{r}} \mu_{0} \mu_{\mathrm{rs}}}{\sigma_{\mathrm{Fe}}}}
$$

Stator referred rotor impedance is obtained by multiplying the impedance given in (7) by the transformation coefficient $\mathrm{k}_{\mathrm{t}}$ is given by:

$$
\mathrm{k}_{\mathrm{t}}=\frac{2 \mathrm{~m}_{1}\left(\mathrm{~N}_{1} \mathrm{k}_{\mathrm{w} 1}\right)^{2}}{\mathrm{p}}
$$

Where $\mathrm{m}_{1}$ is the stator phases number, $\mathrm{N}_{1}$ is the number of turn per phase of stator, $\mathrm{k}_{\mathrm{w} 1}$ is the stator winding factor and $\mathrm{p}$ is the pole pairs number.

The referred to the stator rotor impedance is given by:

$\mathrm{Z}_{\mathrm{r}}^{\prime}=\left(\mathrm{a}_{\mathrm{R}}+\mathrm{ja} \mathrm{a}_{\mathrm{x}}\right) \mathrm{k}_{\mathrm{t}} \mathrm{k}_{\mathrm{z}} \frac{\mathrm{L}}{\tau} \sqrt{\frac{\pi \mathrm{f}_{\mathrm{r}} \mu_{0} \mu_{\mathrm{rs}}}{\sigma_{\mathrm{Fe}}}}$

For positive sequence rotating field $\mathrm{f}_{\mathrm{r}}^{+}=\mathrm{sf}$, proposed stator referred rotor impedance is given by:

$$
\begin{aligned}
& \mathrm{Z}_{\mathrm{r}+}^{\prime}=\left(\mathrm{a}_{\mathrm{R}}+\mathrm{ja}_{\mathrm{x}}\right) \mathrm{k}_{\mathrm{t}} \mathrm{k}_{\mathrm{z}} \frac{\mathrm{L}}{\tau} \sqrt{\frac{\pi s f \mu_{0} \mu_{\mathrm{rs}}}{\sigma_{\mathrm{Fe}}}} \\
& \mathrm{R}_{\mathrm{r}+}^{\prime}=\mathrm{a}_{\mathrm{R}} \mathrm{k}_{\mathrm{t}} \mathrm{k}_{\mathrm{z}} \frac{\mathrm{L}}{\tau} \sqrt{\frac{\pi s f \mu_{0} \mu_{\mathrm{rs}}}{\sigma_{\mathrm{Fe}}}}=\mathrm{a}_{\mathrm{R}} \mathrm{Z}_{\mathrm{c}} \sqrt{\mu_{\mathrm{rs}}} \sqrt{\mathrm{s}} \\
& \mathrm{X}_{\mathrm{r}+}^{\prime}=\mathrm{a}_{\mathrm{X}} \mathrm{k}_{\mathrm{t}} \mathrm{k}_{\mathrm{z}} \frac{\mathrm{L}}{\tau} \sqrt{\frac{\pi s f \mu_{0} \mu_{\mathrm{rs}}}{\sigma_{\mathrm{Fe}}}}=\mathrm{a}_{\mathrm{X}} \mathrm{Z}_{\mathrm{c}} \sqrt{\mu_{\mathrm{rs}}} \sqrt{\mathrm{s}}
\end{aligned}
$$
given by:

For negative sequence rotating field $\mathrm{f}_{\mathrm{r}}^{-}=(2-\mathrm{s}) \mathrm{f}$, proposed rotor impedance referred to stator is

$$
\mathrm{Z}_{\mathrm{r}-}^{\prime}=\left(\mathrm{a}_{\mathrm{R}}+\mathrm{ja} \mathrm{a}_{\mathrm{x}}\right) \mathrm{k}_{\mathrm{t}} \mathrm{k}_{\mathrm{z}} \frac{\mathrm{L}}{\tau} \sqrt{\frac{\pi(2-\mathrm{s}) \mathrm{f} \mu_{0} \mu_{\mathrm{rs}}}{\sigma_{\mathrm{Fe}}}}
$$




$$
\begin{aligned}
& \mathrm{R}_{\mathrm{r}-}^{\prime}=\mathrm{a}_{\mathrm{R}} \mathrm{k}_{\mathrm{t}} \mathrm{k}_{\mathrm{z}} \frac{\mathrm{L}}{\tau} \sqrt{\frac{\pi(2-\mathrm{s}) \mathrm{f} \mu_{0} \mu_{\mathrm{rs}}}{\sigma_{\mathrm{Fe}}}}=\mathrm{a}_{\mathrm{R}} \mathrm{Z}_{\mathrm{c}} \sqrt{\mu_{\mathrm{rs}}} \sqrt{2-\mathrm{s}} \\
& \mathrm{X}_{\mathrm{r}-}^{\prime}=\mathrm{a}_{\mathrm{X}} \mathrm{k}_{\mathrm{t}} \mathrm{k}_{\mathrm{z}} \frac{\mathrm{L}}{\tau} \sqrt{\frac{\pi(2-\mathrm{s}) \mathrm{f} \mu_{0} \mu_{\mathrm{rs}}}{\sigma_{\mathrm{Fe}}}}=a_{X} Z_{c} \sqrt{\mu_{\mathrm{rs}}} \sqrt{2-\mathrm{s}}
\end{aligned}
$$

where $\mathrm{Z}_{\mathrm{c}}=\mathrm{k}_{\mathrm{t}} \mathrm{k}_{\mathrm{z}} \frac{\mathrm{L}}{\tau} \sqrt{\frac{\pi f \mu_{0}}{\sigma_{\mathrm{Fe}}}}$ is the rotor impedance constant value which is independent on the values of slip $\mathrm{s}$ and the surface relative magnetic permeability $\mu_{\mathrm{rs}}$.

The per phase Equivalent circuit for solid-rotor induction motors is shown in Figure 1, the stator core losses are neglected. In equivalent circuit the rotor branch consists of the nonlinear resistance and reactance of rotor, both of them dependent on the slip and solid steel electric and magnetic parameters.

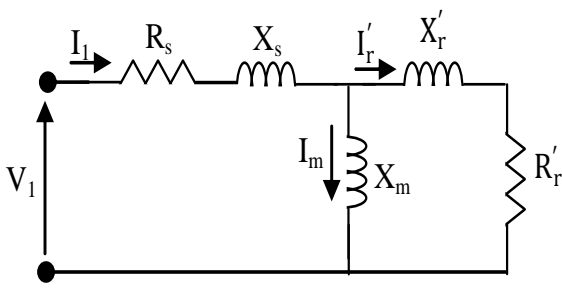

Figure 1. Solid rotor induction motor per phase equivalent circuit

\section{FUZZY NEURAL NETWORKS AECHITECTURE}

Fuzzy logic systems and neural network both are exploiting the processing capability of human-like knowledge [24]. Merging neural network with fuzzy systems into an integrated system in order to reach the benefits of both. The fuzzy neural network FNN architecture is shown in Figure 2 [25]. Every node and layer have its practical meaning. The structure of FNN is based on both fuzzy rules and inference. Each layer shown in Figure 2 will be described as follows [26]:

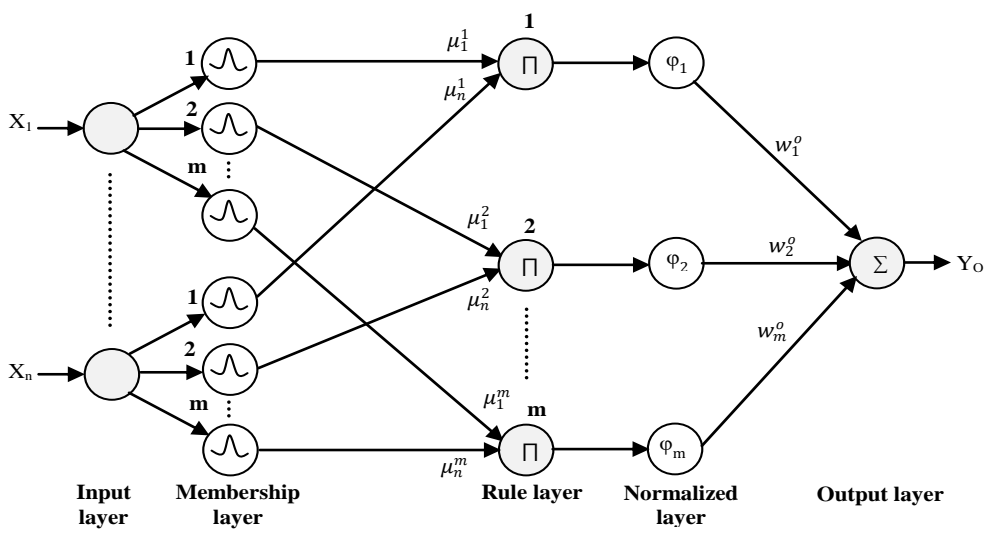

Figure 2. Architecture of fuzzy neural network

1). Input layer: for each input node, $\mathrm{j}$ in this layer transmits the input linguistic variables $\mathrm{x}_{\mathrm{j}}(\mathrm{j}=1,2, . ., \mathrm{n})$ directly to output without changed.

2). Hidden layer I: represent membership layer achieve a membership function, the input of this layer is represented by the output of input layer $\mathrm{x}_{\mathrm{j}}$ which has $\mathrm{m}$ membership function is represented by Gaussian membership functions as:

$$
\mu_{\mathrm{j}}^{\mathrm{i}}=\exp \left(-\frac{\left(\mathrm{x}_{\mathrm{j}}-\mathrm{c}_{\mathrm{ij}}\right)^{2}}{2 \mathrm{~s}_{\mathrm{ij}}{ }^{2}}\right)
$$


where $\exp ($.$) is exponential function, \mathrm{c}_{\mathrm{ij}}$ and $\mathrm{s}_{\mathrm{ij}}(\mathrm{i}=1,2, \ldots, \mathrm{m} ; \mathrm{j}=1,2, \ldots, \mathrm{n})$ respectively, are the Gaussian function center and standard deviation in the $\mathrm{i}^{\text {th }}$ term of the $\mathrm{j}^{\text {th }}$ input of linguistic variable $\mathrm{x}_{\mathrm{n}}$ in the node of this layer.

3). Hidden layer II: represent the rule layer which implements fuzzy inference in each node of this layer and this is represents a possible fuzzy rules If-part. To compute the firing rules the T-norm operaror is used and each node multiplies the input signals and gives the result of the product as outputs. The output of the $\mathrm{i}^{\text {th }}$ neuron in this layer is (17):

$$
\emptyset_{\mathrm{i}}=\prod_{\mathrm{j}}^{\mathrm{n}} \mu_{\mathrm{j}}^{\mathrm{i}}
$$

4). Normalized layer: represent normalized layer the neurons number in this layer is equal to the number of neurons in layer 3 . The output of the $\mathrm{i}^{\text {th }}$ neuron in this layer is (18):

$$
\varphi_{\mathrm{i}}=\frac{\emptyset_{\mathrm{i}}}{\sum_{i=1}^{m} \emptyset_{\mathrm{i}}}
$$

5). Output layer: this layer represents output linguistic variables of each node, which computes the output by the weighted summation of incoming signals as (19):

$$
\mathrm{y}_{0}=\sum_{\mathrm{i}=1}^{\mathrm{m}} \mathrm{w}_{\mathrm{i}}^{0} \varphi_{\mathrm{i}}
$$

where $y_{0}$ is the output variable and $\mathrm{w}_{\mathrm{i}}^{0}$ is the THEN-part of fuzzy rule or weight connection between $i_{\text {th }}$ output of normalized layer and $\mathrm{o}^{\text {th }}$ output.

\subsection{FNN learning algorithm}

The parameters of fuzzy neural network which can be adapted are the center values $\mathrm{c}_{\mathrm{ij}}$ and the values of standard deviation $s_{i j}$ for the Gaussian membership functions. Also, in the consequence part weights values $\mathrm{w}_{\mathrm{i}}^{\mathrm{o}}$ can be adapted. For updating the parameters of FNN a gradient decent back-propagation algorithm is used based on the data of training patterns. The main goal of supervised learning algorithm is to minimize the mean square error is given by [26]:

$$
\mathrm{E}=\frac{1}{2}\left(\mathrm{Y}_{0}-\mathrm{Y}_{\mathrm{d}}\right)^{2}
$$

where $\mathrm{Y}_{0}$ the actual output of FNN and $\mathrm{Y}_{\mathrm{d}}$ is the desired output.

The algorithm of gradient descent for updating the parameter values gives the following iterative equations:

$$
\begin{aligned}
& w i(k+1)=w i(k)-\eta w \frac{\partial E}{\partial \omega i} \\
& \operatorname{cij}(k+1)=c i j(k)-\eta c \frac{\partial E}{\partial c i j} \\
& \operatorname{sij}(k+1)=s i j(k)-\eta s \frac{\partial E}{\partial s i j}
\end{aligned}
$$

where $\eta_{\mathrm{w}}$ is the learning rate for the weight, $\eta_{\mathrm{c}}$ and $\eta_{\mathrm{s}}$ are the learning rate of center and standard deviation in Gaussian function, respectively.

By partial derivative of error function given in (20), we can get the following (24), (25) and (26):

$$
\begin{aligned}
& \frac{\partial \mathrm{E}}{\partial \mathrm{wi}}=\left(\mathrm{Y}_{0}-\mathrm{Y}_{\mathrm{d}}\right) \varphi_{\mathrm{i}} \\
& \frac{\partial \mathrm{E}}{\partial \mathrm{cij}}=\left(\mathrm{Y}_{0}-\mathrm{Y}_{\mathrm{d}}\right) w i \varphi_{\mathrm{i}} \frac{(\mathrm{xj}-\mathrm{cij})}{\mathrm{sij}^{2}} \\
& \frac{\partial \mathrm{E}}{\partial \mathrm{sij}}=\left(\mathrm{Y}_{0}-\mathrm{Y}_{\mathrm{d}}\right) w i \varphi_{\mathrm{i}} \frac{(\mathrm{xj}-\mathrm{cij})^{2}}{\mathrm{sij}^{3}}
\end{aligned}
$$


Substituting (24), (25), and (26) into (21), (22), and (23), respectively, the new values of $\mathrm{w}_{\mathrm{i}}, \mathrm{c}_{\mathrm{ij}}$, and $\mathrm{s}_{\mathrm{ij}}$ after adaptation are given by (28) and (29):

$$
\begin{aligned}
& \operatorname{wi}(k+1)=w i(k)-\eta w\left(Y_{0}-Y_{d}\right) \varphi_{i} \\
& \operatorname{cij}(k+1)=\operatorname{cij}(k)-\eta c\left(Y_{0}-Y_{d}\right) w i \frac{(x j-c i j)}{s i j^{2}} \\
& \operatorname{sij}(k+1)=s i j(k)-\eta s\left(Y_{0}-Y_{d}\right) w i \varphi_{i} \frac{(x j-c i j)^{2}}{s i j^{3}}
\end{aligned}
$$

\section{TURN FAULTS OF STATOR WINDING}

To develop diagnosis method for small percent of stator winding of high speed solid rotor induction motor which are exposed to inter-turn and turn to earth faults inside each phase, the model of stator circuit shown in Figure 3 is considered as inter-turn and turn to earth or phase to ground faults cases. The under consideration fault case can be either single-phase or multi-phase. The position of fault cases are modeled in equivalently method to be around the neutral point N. Eight cases of inter-turn short circuit and eight cases of turn to earth short circuits in stator winding for each phase with winding ratio of 3\%, 5\%, 7\%, 10\%, 13\%, $15 \%, 17 \%$, and $20 \%$ are extracted to simulate any fault case. Table 1 show the parameters of a high speed solid rotor induction motor with star connected winding which is used in the simulated model where the solid rotor core is manufacturing from ferromagnetic material.

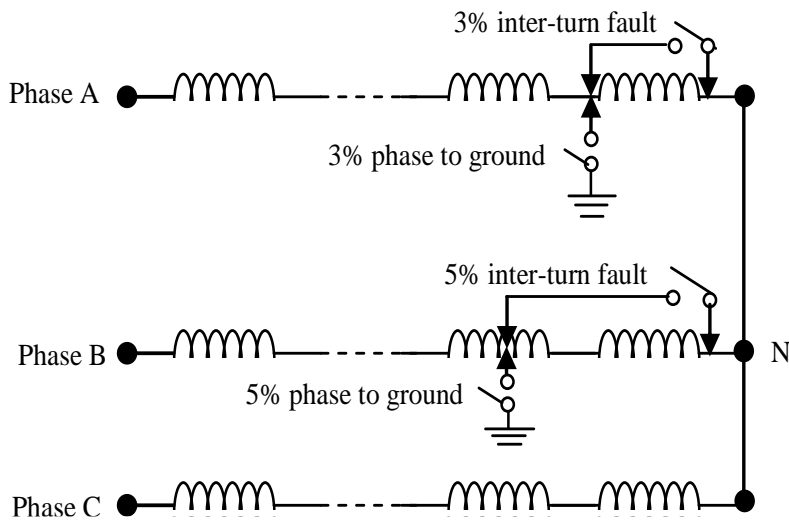

Figure 3. Stator winding turn faults

Table 1. Parameters of simulated solid rotor motor

\begin{tabular}{lr}
\hline \multicolumn{1}{c}{ Parameters } & Value (unit) \\
\hline Power & $120 \mathrm{KW}$ \\
Voltage & $400 \mathrm{~V}$ \\
Frequency $(\mathrm{f})$ & $140 \mathrm{~Hz}$ \\
No. of poles $(\mathrm{P})$ & 2 \\
Synchronous speed $\left(\mathrm{N}_{\mathrm{s}}\right)$ & 8400 r.p.m \\
No. of stator turn per phase & 16 \\
Rotor length $(\mathrm{L})$ & $280 \mathrm{~mm}$ \\
Pole pitch $(\tau)$ & $5 \mathrm{~mm}$ \\
Surface relative magnetic permeability $\left(\mu_{\mathrm{rs}}\right)$ & $100 \mathrm{H} / \mathrm{m}$ \\
Rotor conductivity $\left(\sigma_{\mathrm{Fe}}\right)$ & $5^{*} 10^{6} \mathrm{~S} / \mathrm{m}$ \\
Resistance coefficient $\left(\mathrm{a}_{\mathrm{R}}\right)$ & 1.45 \\
Reactance coefficient $\left(\mathrm{a}_{\mathrm{X}}\right)$ & 0.85 \\
Edge effect factor $\left(\mathrm{k}_{\mathrm{z}}\right)$ & 1.011374 \\
Transformation coefficient $\left(\mathrm{K}_{\mathrm{t}}\right)$ & 1536 \\
\hline
\end{tabular}

\section{PROPOSED METHOD FOR FAULTS DIAGNOSIS}

In this section, the proposed approach for stator winding inter-turn and turn to ground fault diagnosis will be explained as shown in Figure 4.

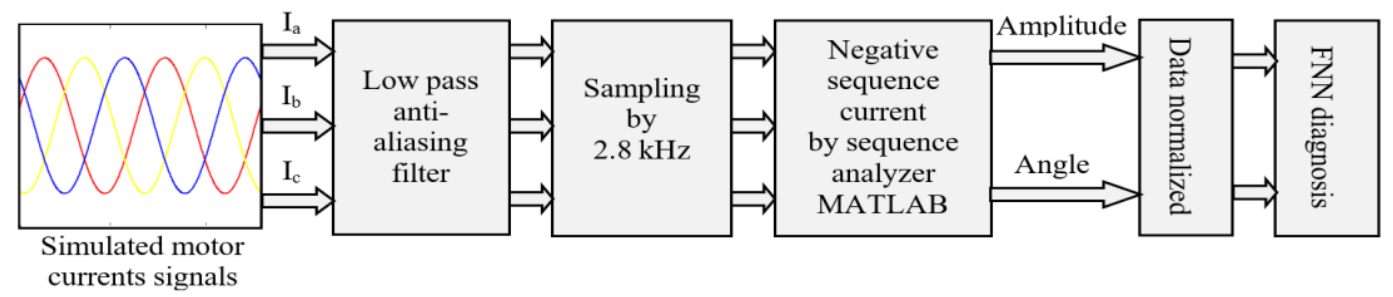

Figure 4. Proposed diagnosis method

The first step in this method is the three-phase current signals from simulated model of motor are measured and filtering by low-pass anti-aliasing filter with cut off frequency of $400 \mathrm{~Hz}$ to prevent the mixing of sampling frequency with current signals frequencies greater than the Nyquist frequency. Then, these

Faults diagnosis in stator windings of high speed solid rotor induction motors ... (Ahmed Thamer Radhi) 
current signals are sampling by sampling frequency of $2.8 \mathrm{kHz}$ to reach 20 sample per cycle and the currents samples are then mesured for one minute in each case. After this step, the three-phase sampling data are sending to the sequence analyzer MATLAB block to obtain the values of amplitude and phase angle of negative sequence current. These data are recorded for healthy operation of motor and under different winding fault conditions. The final step, the data of amplitude and phase angle for negative sequence current are normalized between $(-1,1)$ to feed the fault diagnosis system which consists of proposed fuzzy neural network structure to detect the fault in stator winding under different conditions.

\section{SIMULATION MODEL}

Simulated model of high speed induction motor with solid rotor based on equivalent circuit explained previously in Figure 1 is achieve using MATLAB simulation software. Figure 5 (a) shows the model of one phase such as phase a of the motor winding, this model has been used to extract the data from motor current to learning and testing the proposed fault diagnosis algorithm. In this model the stator winding is subdivided by $3 \%, 5 \%, 7 \%, 10 \%, 13 \%, 15 \%, 17 \%$, and $20 \%$ for producing the required date for inter-turn and turn to earth faults conditions. In this model for healthy condition of motor operation at balanced positive sequence rotating field the rotor impedance inserted into equivalent circuit is according to (10), while in fault condition the negative sequence rotating field is produced in the air-gap mmf of the motor, therefore, the rotor impedance inserted into equivalent circuit is according to (13). Similarly, the other two phases are simulated and the complete simulated model for solid-rotor induction motor is shown in Figure 5 (b).

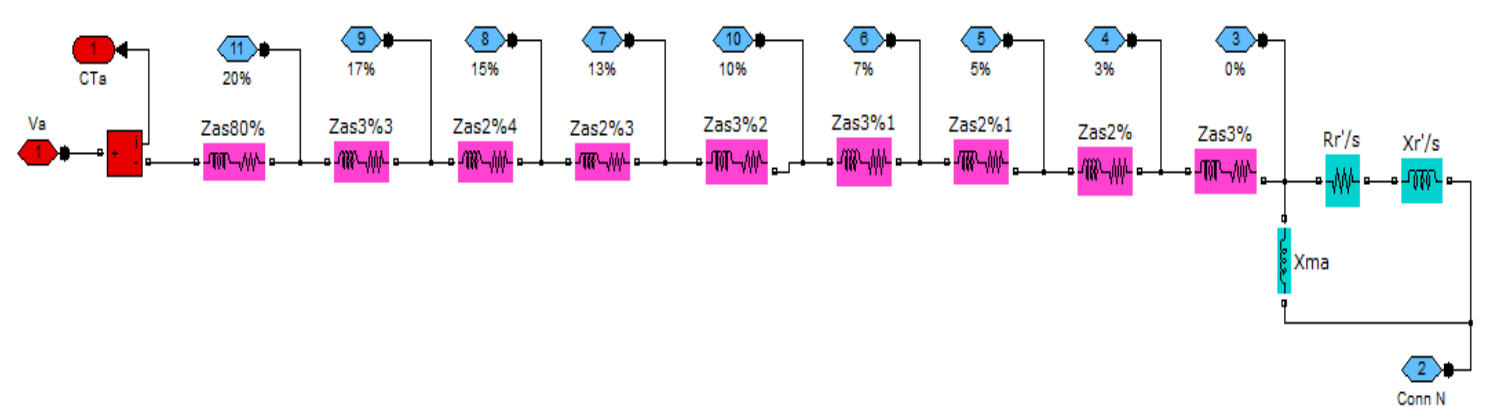

(a)

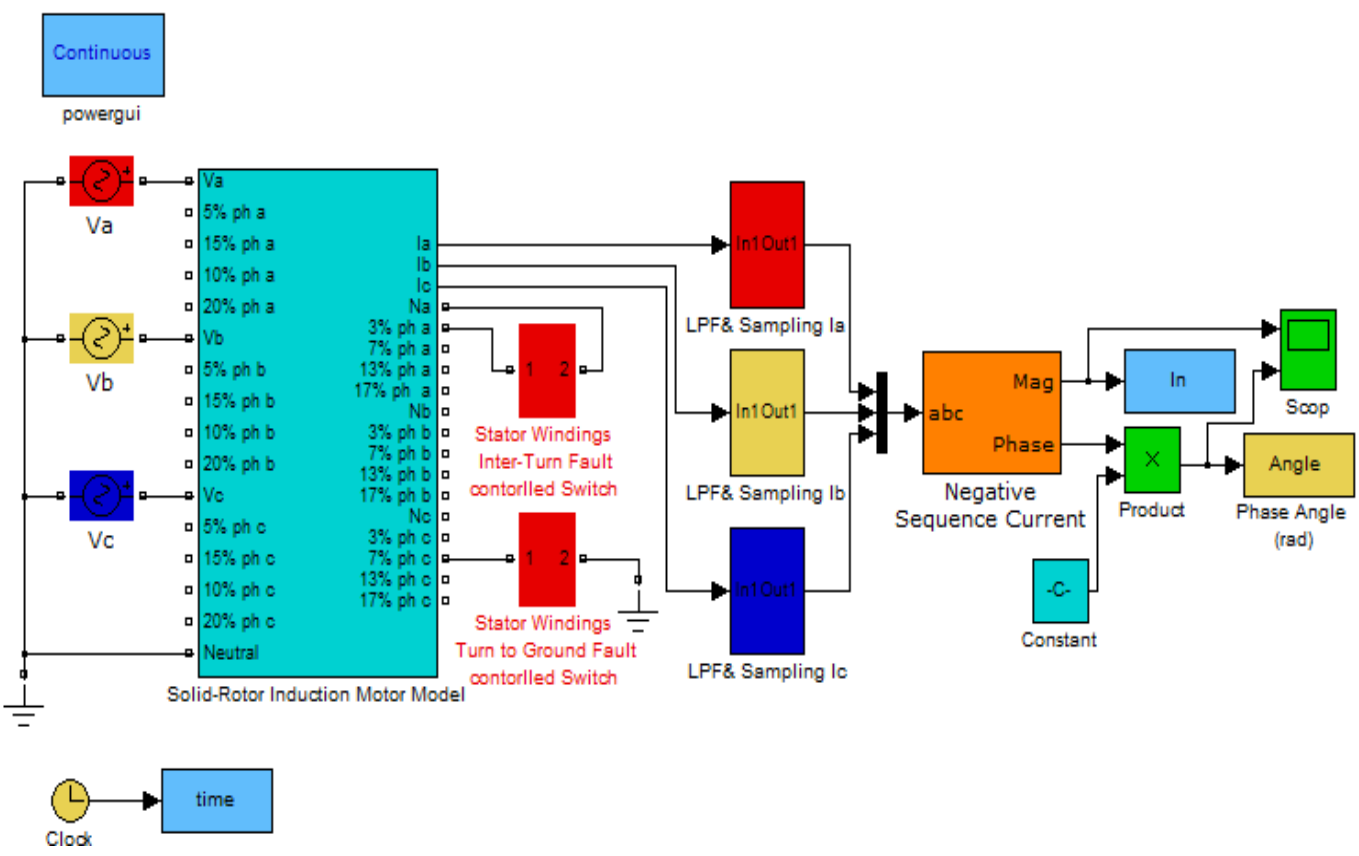

(b)

Figure 5. Simulink model of high speed solid-rotor induction motor, (a) phase a, (b) complete model 


\section{TRAINING OF PROPOSED FNN}

Ten sample data were taken in input layer of proposed FNN to process the input data which contain 5 samples for each input, there are two inputs in the model, amplitude of negative sequence current and phase angle, therefore, the input layer required 10 input nodes. The FNN with 33 rules in its hidden layer were chosen in proposed network which are resulted in good accuracy from various networks with different nodes number in its hidden layer. Output layer has one node which has 0 value for healthy cases and has 1 value for faulty cases to diagnosis the faults.

The faults cases in stator winding of motor are includes winding percent of $3 \%, 5 \%, 7 \%, 10 \%, 13 \%$, $15 \%, 17 \%$, and $20 \%$ for inter-turn fault and turn to earth fault for each phase. Also, there are five health cases for normal operation of motor with no fault are considered in training process in which are the operation of solid rotor induction motor with no load, with $25 \%$ of load, with $50 \%$ of load, with $75 \%$ of load, and with $100 \%$ load. The faults cases were simulated with three different incident time of fault in motor currents signals, therefore, the totally number of training sets is equal to (8-Inter-turn +8 -turn to earth) times three phases which are extracted for three incidence time, so, there are 144 sets in addition to 5 normal sets, hence the total number of data patterns are 149 sets produced to the proposed FNN network. Totally, 100 data sets were used for training and 49 data sets were used for testing the FNN fault diagnosis approach. The Backpropagation algorithm was used to learn the network according to training algorithm explained previously in section 3.1. The mean square error during the learning process was 0.001 and the learning rates of weight, Gaussian function center and standard deviation for FNN are $\left(\eta_{\mathrm{w}}=0.05, \eta_{\mathrm{c}}=0.0014\right.$ and $\left.\eta_{\mathrm{s}}=0.007\right)$, respectively. The training of mean square error for FNN with number of epoch is shown in Figure 6 and this error is convergence after 2564 epochs. The learning of one element of weight w, one element of center c, and one element of standard s for FNN during 2564 epochs are shown in Figures 7, 8 and 9, respectively.

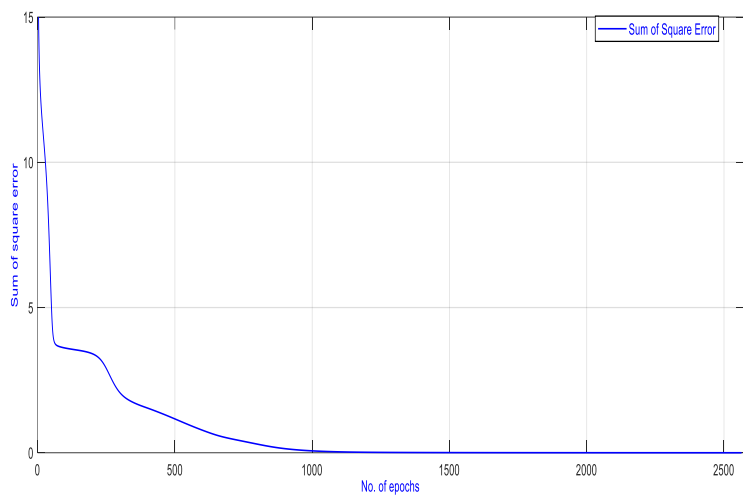

Figure 6. Mean square error during 2564 epochs

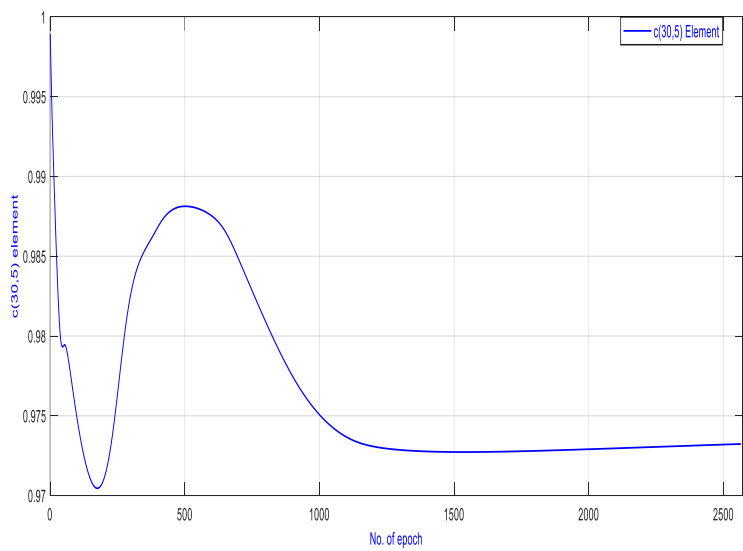

Figure 8. Center c during 2564 epochs

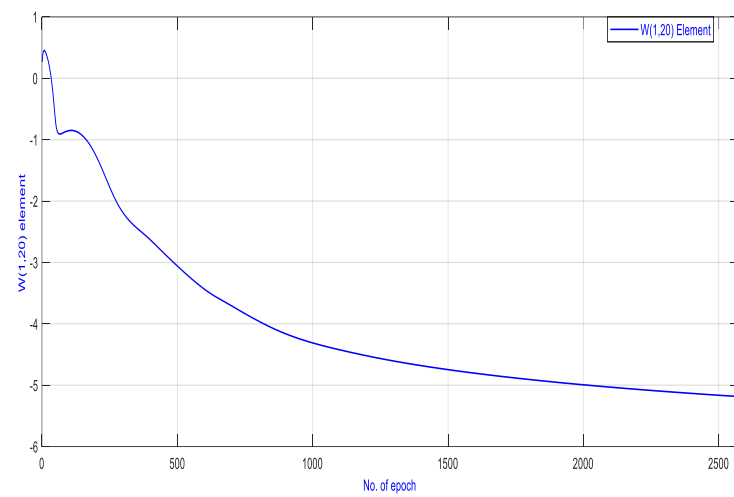

Figure 7. Weight w during 2564 epochs

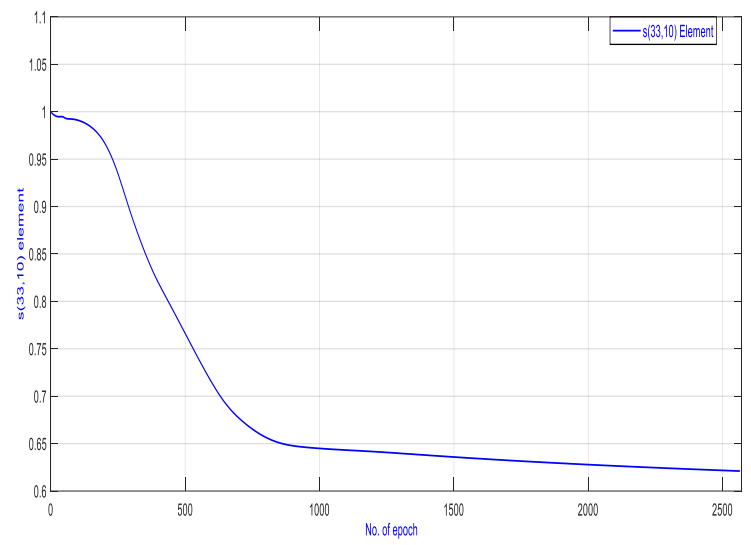

Figure 9. Standard s during 2564 epochs 


\section{RESULTS AND DISCUSSION}

During the tests results it is convenient to consider a factor is greater than zero for amplitude of negative sequence current $I_{n}$ in healthy cases in order to avoid noise effect, intrinsic stator winding asymmetries and voltages unbalance. The three-phase motor current, amplitude of $I_{n}$ and phase angle of $I_{n}$ for motor operation in healthy condition is shown in Figure 10 (a), for 3\% inter-turn short circuit in phase a is shown in Figure 10 (b), and for 3\% turn to earth short circuit in phase b is shown in Figure 10 (c), respectively.

The results of simulation are shown in Table 2 were carried out through simulation time of 2 sec which is represent about 280 cycle of current signals of motor operation. The tests include healthy operation of motor and different faults conditions in stator winding of the motor with different faults incidence time during the simulation time. All the faults cases occur during the operation of motor at full load. It is seen that the output of proposed FNN approach gives a value of 0 for no fault cases and gives a value of 1 for faulty cases. The results shows that the FNN diagnosis method is fast and gives good response for faults diagnosis at different cases in the stator winding in each phase of the motor. Examples of simulation tests are carried out during healthy operation of motor and under different faults conditions. Figure 11 shows the operation of motor with no faults, therefore, the FNN output indicate value of zero. Turn to earth fault of $10 \%$ of stator winding into phase a, which occurs at time of $42 \mathrm{~ms}$ of motor operation time is shown in Figure 12. It is seen that FNN output has value of 1 at the instant of fault start to detect the fault.

Table 2. Tests results

\begin{tabular}{|c|c|c|c|}
\hline Fault cases & Stator winding conditions & $\begin{array}{c}\text { Fault incidence time }=100 \\
\text { ms } \\
\text { FNN output }\end{array}$ & $\begin{array}{c}\text { Fault incidence time }=250 \\
\text { ms } \\
\text { FNN output }\end{array}$ \\
\hline Normal at no-load & Healthy & 0.0038 & 0.0031 \\
\hline Normal at half load & Healthy & 0.0001 & 0.0037 \\
\hline Normal at full load & Healthy & 0.0018 & 0.0015 \\
\hline Inter-turn fault & $3 \%$ Phase a & 0.9989 & 1 \\
\hline Inter-turn fault & $5 \%$ Phase a & 1 & 0.9998 \\
\hline Inter-turn fault & $7 \%$ Phase b & 0.9998 & 1 \\
\hline Inter-turn fault & $10 \%$ Phase b & 0.9999 & 1 \\
\hline Inter-turn fault & $13 \%$ Phase c & 1 & 0.9988 \\
\hline Inter-turn fault & $20 \%$ Phase c & 1 & 1 \\
\hline Turn to earth fault & $3 \%$ Phase a & 0.9999 & 1 \\
\hline Turn to earth fault & $15 \%$ Phase a & 0.9944 & 1 \\
\hline Turn to earth fault & $3 \%$ Phase $b$ & 1 & 0.9889 \\
\hline Turn to earth fault & $5 \%$ Phase b & 1 & 0.9899 \\
\hline Turn to earth fault & $10 \%$ Phase c & 0.9983 & 1 \\
\hline Turn to earth fault & $17 \%$ Phase c & 1 & 0.9977 \\
\hline Inter-turn multi phase fault & $7 \%$ Phase a $13 \%$ phase $b$ & 0.9962 & 0.9943 \\
\hline Inter-turn multi phase fault & $10 \%$ Phase a $17 \%$ phase b $3 \%$ phase $c$ & 1 & 0.999 \\
\hline $\begin{array}{l}\text { Turn to earth multi phase } \\
\text { fault }\end{array}$ & $\begin{array}{l}15 \% \text { phase } \mathrm{b} \\
5 \% \text { phase } \mathrm{c}\end{array}$ & 0.9971 & 1 \\
\hline $\begin{array}{l}\text { Turn to earth multi phase } \\
\text { fault }\end{array}$ & $13 \%$ phase a $20 \%$ phase b $7 \%$ phase c & 1 & 0.9986 \\
\hline
\end{tabular}

Figure 13 shows $20 \%$ inter-turn short circuit into phase b and $13 \%$ turn to earth fault into phase c are occurs at time of $59 \mathrm{~ms}$, the FNN output gives value of zero before the fault start time and gives value of 1 at incidence time of fault. Turn to earth short circuit occurs at $17 \%$ of winding of phase a, at $20 \%$ of winding turn to earth short circuit into phase b, and at $20 \%$ inter-turn short circuit into winding of phase c which are occurs at fault start time of $12 \mathrm{~ms}$ and finish at fault end time of $76 \mathrm{~ms}$ is shown in Figure 14. From Figure 14 it is seen that FNN output show value of 1 at fault start time and show value of zero starting from fault end time. As seen, that from examples of simulation tests the proposed FNN fault diagnosis method is effective approach to diagnosis the faults into stator winding of high speed solid rotor induction motors.

The testing accuracy of the proposed fuzzy neural net FNN diagnosis approach is comparing with the results accuracy of the detection technique has been presented in [12] which have proposed diagnosis method of faults in stator winding of permanant magnet synchronous motor PMSM based on self organizing feature map neural networks SOM-NN. The comparison has been made for healthy operation, inter-turn fault, and phase to ground fault as shown in Table 3. It is seen that the proposed FNN diagnosis method has test accuracy higher than that of the previous work such as Elman neural network ELMNN and proposed SOM-NN method which are recorded in [12]. The comparison shows that the proposed FNN algorithm is efficient and has high accuracy to detect the fault under all condition of motor operation. 

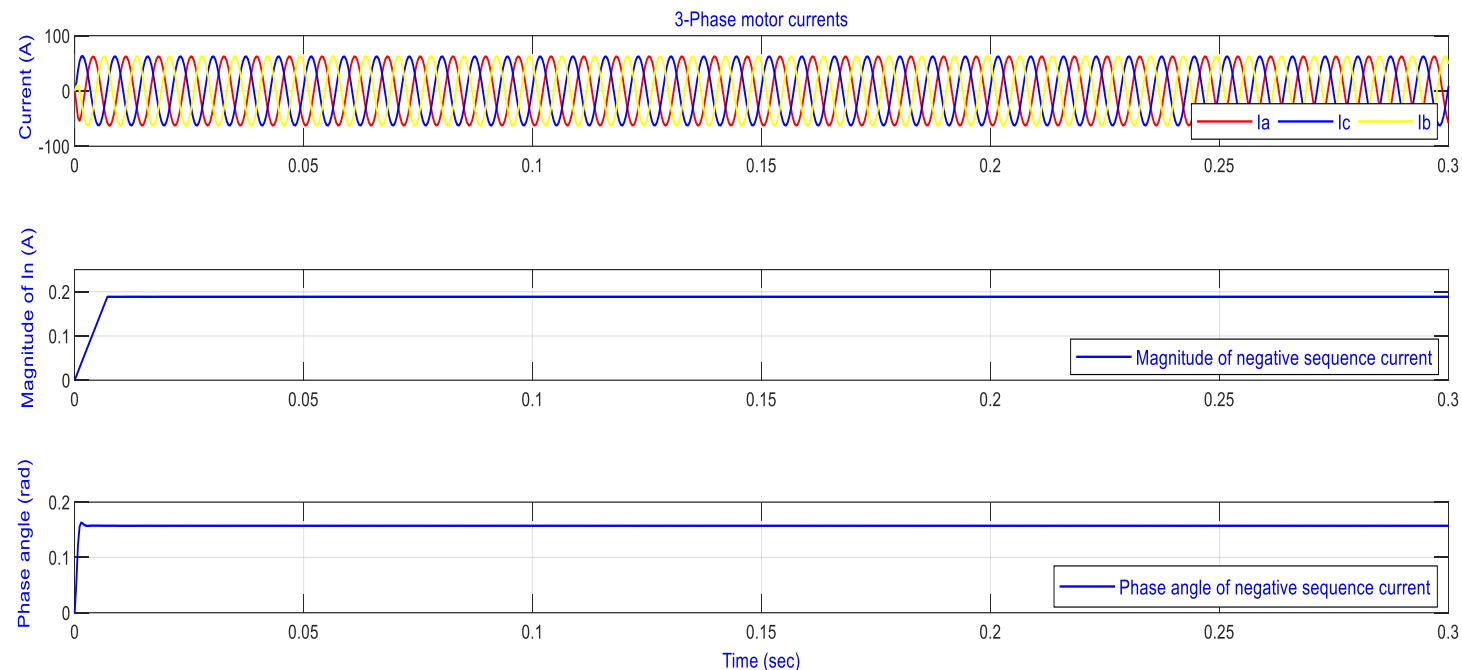

(a)
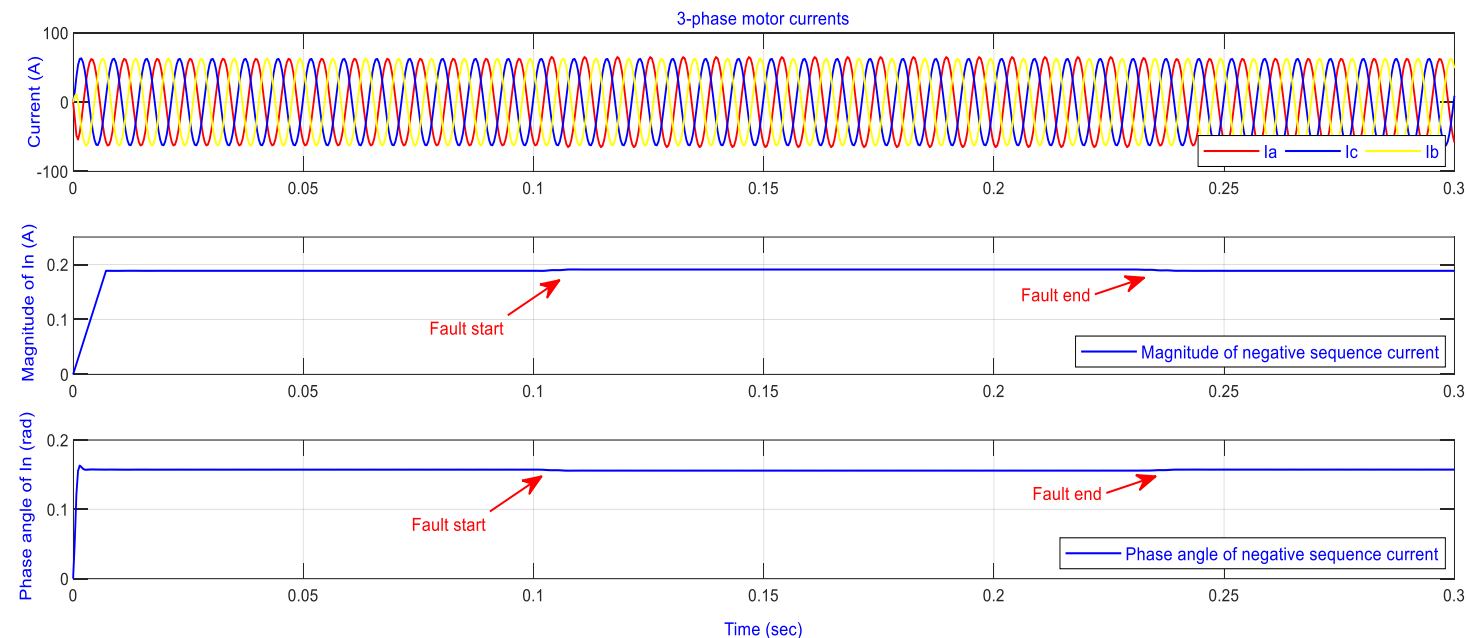

(b)

3-phase motor current
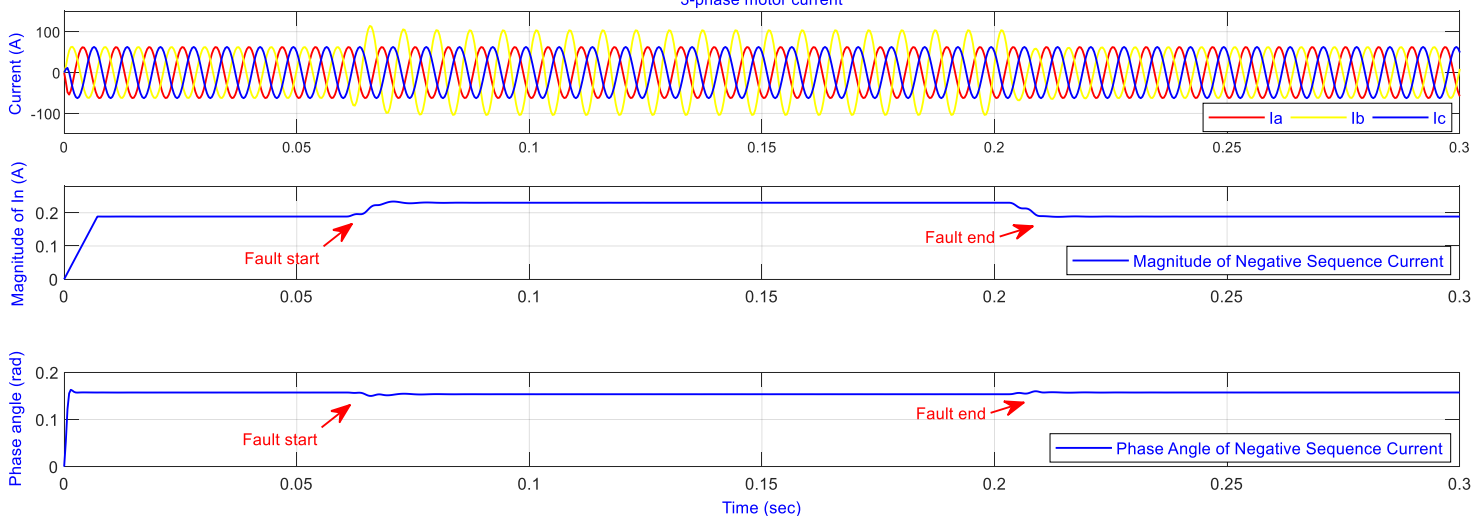

(c)

Figure 10. Motor currents, amplitude of $I_{n}$ and phase angle of $I_{n}$, (a) healthy condition, (b) $3 \%$ inter-turn short circuit phase a, (c) $3 \%$ turn to earth short circuit phase $b$ 


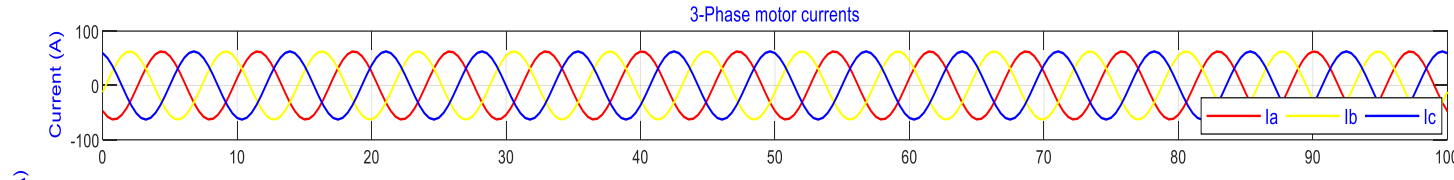

$\varangle$
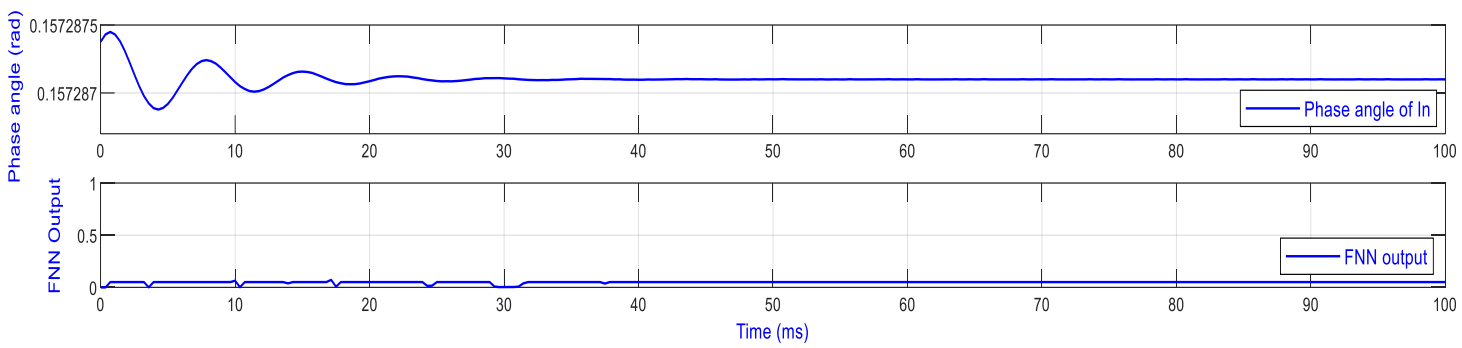

Figure 11. Healthy operation
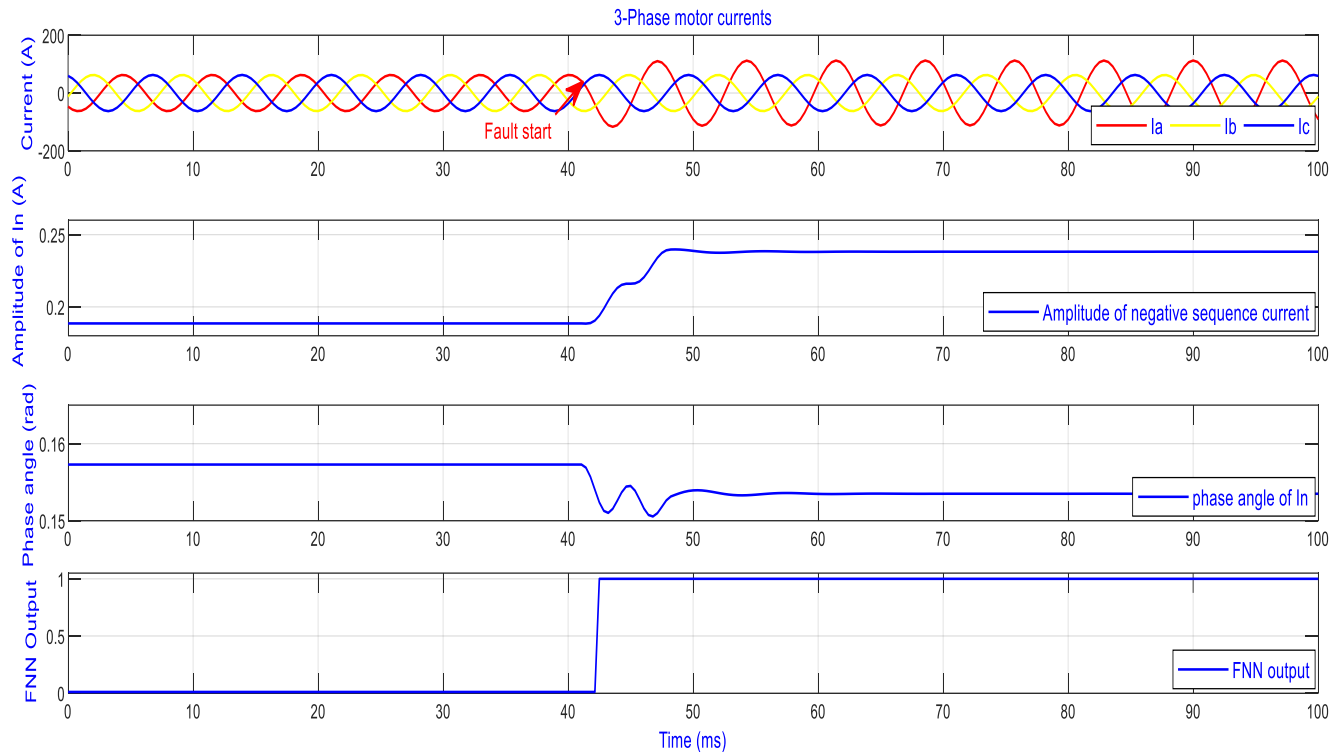

Figure $12.10 \%$ Phase a turn to earth fault 

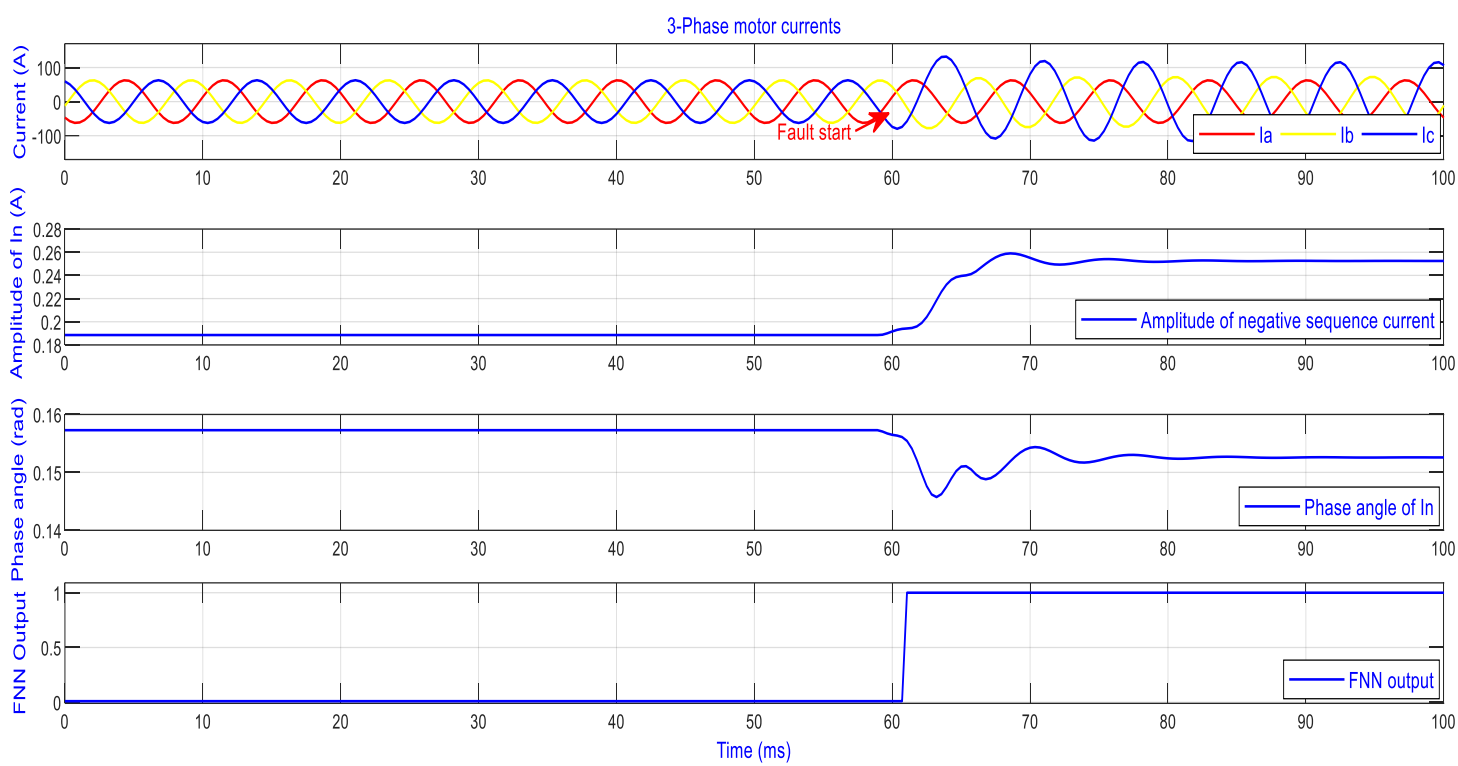

Figure $13.20 \%$ inter-turn phase $\mathrm{b}$ and $13 \%$ turn to earth phase c fault
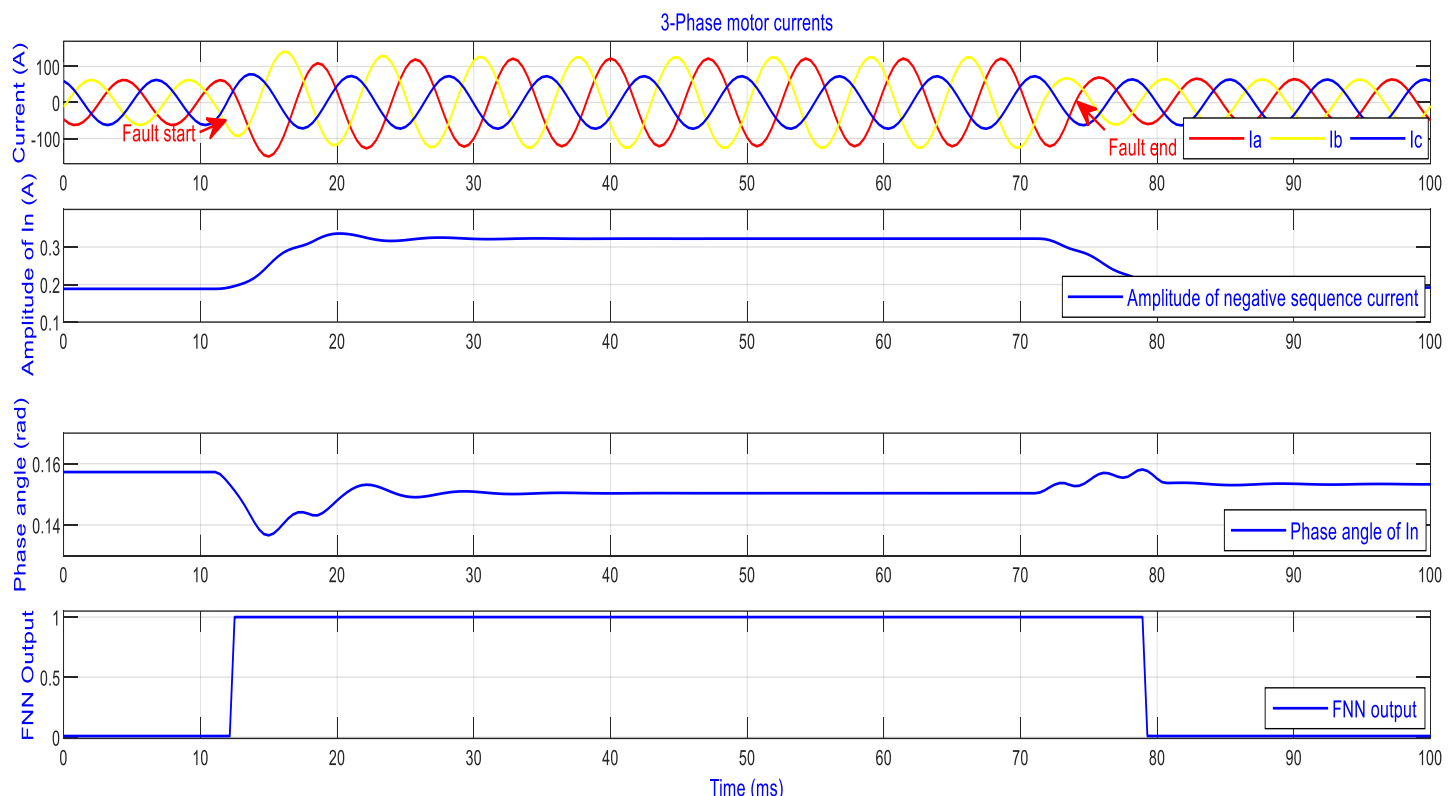

Figure $14.17 \%$ turn to earth phase a, $20 \%$ turn to earth phase b and $20 \%$ inter-turn phase c fault

Table 3 Comparison of tests results

\begin{tabular}{cccc}
\hline \multirow{2}{*}{ Condition } & \multicolumn{3}{c}{ Test accuracy 100\% } \\
& ELMNN [12] & SOM-NN [12] & Proposed FNN \\
\hline Healthy & $97.6 \%$ & $100 \%$ & $100 \%$ \\
Inter-turn fault & $95.9 \%$ & $95 \%$ & $100 \%$ \\
Phase to ground fault & $89.2 \%$ & $88 \%$ & $98 \%$ \\
\hline
\end{tabular}

\section{CONCLUSION}

New method is proposed in this paper for faults diagnosis in stator winding for high speed induction motors with solid rotor. The proposed method is based on amplitude and phase angle of negative sequence 
current of motor. A FNN diagnosis algorithm is used to detect the inter-turn and turn to earth short circuit in stator winding of motor. Results of simulation tests shows that the performance of the whole fault diagnosis approach has been valid for solid rotor induction motor and is effectively detecting the faults in stator winding of motor under different conditions of faults. Therefore, the proposed diagnosis method can improve the stator winding protection of high speed solid rotor induction motors from extra damage and can be developed to diagnosis the other types of motor stator winding faults.

\section{REFERENCES}

[1] T. Aho, J. Nerg and J. Pyrhonen, "Optimizing the axial length of the slitted solid iron rotor," in 2007 2nd IEEE Conference on Industrial Electronics and Applications, pp. 255-259, 2007.

[2] J. Pyrhonen, J. Nerg, P. Kurronen and U. Laiber, "High-speed high-output solid-rotor induction motor technology for gas compression," IEEE Tranactions On Industrial Electronics, vol. 57, no.1, pp. 272-280, Jan 2010.

[3] J. Gieras and J. Saari, "Performance calculation for a high-speed solid rotor induction motor," IEEE Transactions on Industrial Electronics, vol. 59, no. 6, pp. 2689-2700, 2012.

[4] L. Papini, C. Gerade, D. Gerade and A. Mebark, "High speed solid rotor induction machine: analysis and performances," in 2014 17th International Conference on Electrical Machines and Systems (ICEMS), pp. 2759$2765,2014$.

[5] J. E. Q. Mendez, "Stator winding fault detection for a PMSM using fuzzy logic classifier and neural network model identification," M. Sc. Thesis, Florida State University, USA, 2008.

[6] F. Briz and M. W. Degner, "Stator windings fault diagnosis of induction machines operated from inverters and soft-starters using high-frequency negative-sequence currents," IEEE Transactions on Industry Applications, vol. 45, no. 5, pp. 1637-1646, 2009.

[7] P. Wang and L. Shi, "Inter-turn short circuit fault diagnosis of induction motors using the SVM optimized by barebones particle swarm optimization," Journal of Theoretical and Applied Information Technology, vol. 45, no. 2, pp. 573-578, 2012.

[8] V. V. Kuptsov, A. S. Sarvarov and M. Y. Petushkov, "A new approach to analysis of induction motors with rotor faults during startup based on the finite element method," Progress in Electromagnetics research B, vol. 45, pp. 269-290, 2012.

[9] A. A. S. Khan, A. R. Chowdhury and M. S. Haque, "Monitoring and detection health of a single phase induction motor using data acquisition interface (DAI) module with artificial neural network," Wseas Transactions on Systems and Control, vol. 9, pp. 229-237, 2014.

[10] M. Cheng, J. Hang and J. Zhang, "Overview of fault diagnosis theory and method for permanent magnet machine," Chinese Journal of Electrical Engineering, vol. 1, no. 1, pp. 21-36, Dec 2015.

[11] F. Cira, M. Arkan and B. Gumus, "Detection of stator winding inter-turn short circuit faults in permanent magnet synchronous motors and automatic classification of fault severity via a pattern recognition system," Journal of Electrical Engineering and Technology, vol. 11, no. 2, pp. 416-424, 2016.

[12] C. Chuang, Z. Wei, W. Zhifu and L. Zhi, "The diagnosis method of stator winding faults in PMSMs based on SOM neural nteworks," Energy Procedia 105, pp. 2295-2301, 2017.

[13] K. J. Parekh and S. K. B. B. Solanki, "Analysis of the induction motor used in temperature controller machine by condition based monitoring system," International Journal of Science Technology \& Engineering, vol. 3, no. 10, pp. 154 -162, April 2017.

[14] M. A. Sheikh, N. M. Nor, T. Ibrahim, S. T. Bakhsh, M. Irfan and N. B. Saad, "An intelligent automated method to diagnose and segregate induction motor faults," Journal of Electrical Systems, vol. 13, no. 2, pp. 241-254, 2017.

[15] A. b. Ammar, Y. Gritli and M. Benrejeb, "Diagnosis of stator asymmetry in permanent magnet synchronous motors using negative sequence current," Studies in Information and Control, vol. 27, no. 2, pp. 165-174, 2018.

[16] M. Hadef, D. Zaroure and A. Algeria, "PMSM stator winding short circuit fault diagnosis via neural network, "Journal of Automation \& Systems Engineering, vol. 12, no. 4, pp. 25-37, 2018.

[17] Y. Chen, S. Liang, W. Li., H. Liang and C. Wang, "Faults and diagnosis methods of permanent magnet synchronous motors: a review," Applied Sciences, vol. 9, no. 10, p. 2116, 2019.

[18] G. Rajamany, S. Srinivasan, K. Rajamany and R. K. Natarajan, "Induction motor stator inter turn short circuit fault detection in accordance with line current sequence components using artificial neural network," Journal of Electrical and Computer Engineering, vol. 2019, 2019.

[19] R. Selcuk and Z. Dogan, "A dignosis of stator winding fault based on empirical mode decomposition in PMSMs," Balkan Journal of Elecrical \& Computer Engineering, vol. 8, no. 1, pp. 73-80, Jan 2020.

[20] L. Yi, Y. Liu, W. Yu and J. Zhao, "A novel nonlinear observer for fault diagnosis of induction motor," Journal of Algorithms \& Computational Technology, vol. 14, pp. 1-11, 2020.

[21] J. Tang, Y. Yang, J. Chen, R. Qiu and Z. Liu, "Characteristics analysis and measurement of inverter-fed induction motors for stator and rotor fault detection," Energies, vol. 13, no. 1, p. 101, 2020.

[22] A. T. Radhi, "Detection and localization of asymmetry in stator winding of three phase induction motors based on fuzzy neural petri net," Journal of Engineering Science and Technology, vol. 15, no. 4, pp. 2379-2394, 2020.

[23] G. Sutmann, "Compact finite difference schemes of sixth order for the helmholtz equation," Journal of Computational and Applied Mathematica, vol. 203, no. 1, pp. 15-31, 2007. 
[24] C. H. Lee and C. C. Teng, "Identification and control of dynamic systems using recurrent fuzzy neural networks," IEEE Transactions on Fuzzy Systems, vol. 8, no. 4, pp. 349-366, 2000.

[25] C. T. Leondes, Fuzzy logic and expert systems applications, USA: Academic Press, 1998.

[26] R. J. Wai and C. C. Chu, "Robust petri fuzzy-neural-network control for linear induction motor drive," IEEE Transactions on Industrial Electronics. vol. 54, no.1, pp. 177-189, 2007. 